Accumulation of desethylamiodarone has been implicated in other adverse effects of amiodarone treatment. ${ }^{5}$ Its accumulation within the epididymis of this man may have been related to the epididymal pain and swelling. The concentration of desethylamiodarone in the semen was five times that in the serum. The only other recorded seminal concentration of desethylamiodarone, in a patient with discoloured brown semen but no epididymitis, did not exceed the serum concentration. ${ }^{2}$ Isolated epididymitis occurred in our patient after a dose of amiodarone which resulted in a serum concentration within the therapeutic range. We recommend that the serum concentration should be used only as a guide to treatment and that the minimum dose be given. In this case treatment was resumed with a smaller dose which still controlled arrhythmia. The manufacturers of amiodarone have been informed of two other cases of epididymitis associated with the drug, one of which resolved after amiodarone was withdrawn and the other after the dose was reduced.

1 Hutchings A, Spragg BP, Routledge PA. High-performance liquid chromatographic assay of amiodarone and desethylamiodarone in plasma. $f$ Chromatogr 1986;382:386-93.

2 Haffajee CI, Love JC, Canada AT, et al. Clinical pharmacokinetics and efficacy of amiodarone for refractory tachyarrhythmias. Circulation 1983;67:1347-55.

3 Adams PC, Holt P, Holt DW. Amiodarone in testis and semen. Lancet 1985;i:341.

4 Gasparich JP, Mason JT, Greene L, et al. Amiodarone-associated epididymitis: drug-related epididymitis in the absence of infection. I Urol 1985;133:971-2.

5 Fraser AG, Stephens MR, Newcombe RG, Holt DW. Association of serum desethylamiodarone concentration with adverse effects of amiodarone. Br $\mathcal{J}$ Clin Pharmacol 1984;18:276P.

(Accepted 16 September 1987)

Departments of Clinical Pharmacology and Toxicology, Llandough Hospital, Penarth, South Glamorgan CF6 1XX

M J WARD, DM, MRCP, lecturer

P A ROUTLEDGE, MD, FRCP, reader

A HUTCHINGS, PHD, senior medical laboratory scientific officer

Llantwit Major, South Glamorgan CF6 9ST

J M MORRIS, MB, general practitioner

Correspondence to: Dr Ward.

\section{Risk factors for death from meningitis}

Lumbar puncture in suspected meningitis may lead to tentorial herniation (coning) when the intracranial pressure is high. After recent correspondence $e^{1-4}$ we identified features of meningitis in our patients that were associated with coning and death.

\section{Patients, methods, and results}

Using Hospital Activity Analysis data, data from necropsies, and intensive care records we identified 584 children admitted to the Royal Manchester and Booth Hall Children's Hospitals between 1974 and 1985 with a diagnosis on discharge of meningitis. Both hospitals are tertiary referral centres. Thirty two children died, 13 of whom were excluded from this study because of malformations of the central nervous system or because they were neonates who had suffered complications of prematurity or low birth weight. The 19 other children (the study group) were paired with a control patient: the next consecutive child with meningitis most closely matching the study child's year of admission, sex, age, and infecting micro-organism but who recovered. All children had a lumbar puncture.

Case notes were examined for mention of signs associated with raised intracranial pressure. The parent's account of their child's illness at home and the $\mathbb{D}$ doctor's notes on admission were examined for evidence of impaired consciousness and fits. Necropsies were performed on 13 of the 19 children. Four children had suffered coning. The frequency of each feature in those who had and had not $\bigcirc$ suffered coning was compared. Comparison of frequencies between groups was made with a $\chi^{2}$ test or Fisher's exact test. For each symptom and sign the relative $D$ risk of death and coning was calculated with $95 \%$ confidence intervals.

One of the study group was matched for all four factors, seven were matched for three factors, 10 for two factors, and one for one factor. The bacteria were identified in 13 of the study group and 17 controls; they were matched in four of the pairs. On arrival at hospital fits and a Glasgow coma scale scores of under eight both carried a significant risk of death. Although the relative risks of death were $\stackrel{5}{\rightarrow}$ increased with parental observation at home of children jerking their limbs, 0 twitching their faces, stopping breathing, or appearing blue, these were not significant. The data from necropsy showed that the relative risk of coning for the same factors was increased, although not significantly.

\section{Comment}

Were the children who died the most ill, or did lumbar puncture predispose them to coning and precipitate death? The relative risk of coning $\vec{\omega}$ was greater than two when fits and impaired consciousness were considered as separate risk factors for coning in the group of 13 who underwent necropsy.

While accepting the drawbacks of our approach, we believe that the $\mathscr{C}$ results suggest caution when deciding to do a lumbar puncture on a child with clinically diagnosed meningitis who is also exhibiting signs associated $O$ with raised intracranial pressure. Doctors, meanwhile, face the problem of $\vec{A}$ an unconscious child in whom meningitis is suspected. Here the only safe $\tilde{O}$ approach is to take blood cultures and swabs for bacterial and virological study, but not to do a lumbar puncture. Antibiotic treatment for bacterial meningitis in which the causative organism is unknown should be started. N For those with a Glasgow coma score of seven or less intracranial pressure should be monitored and actively managed and computed tomography of the brain considered. Lumbar puncture should be reserved until a degree of recovery allows it to be performed safely and diagnostic worries still persist. Monitoring of intracranial pressure in these circumstances can be carried out $\vec{\oplus}$ by using an intraventricular catheter, which also provides cerebrospinal $\infty$ fluid for analysis.

1 Harper JR, Lorber J, Hillas Smith G, Bower BD, Eykyn SJ. Timing of lumbar puncture in severe childhood meningitis. Br Med f 1985;291:651-2.

MacVicar D, Symon DNK. Timing of lumbar puncture in severe childhood meningitis. BrMed $\mathcal{f}$ 1985;291:898.

3 Clarke MA. Timing of lumbar puncture in severe childhood meningitis. Br Med f 1985;291:899.

4 Stephenson JBP. Timing of lumbar puncture in severe childhood meningitis. Br Med $\mathrm{f}$ 1985;291:1123.

5 Teasdale G, Jennett B. Assessment of coma and impaired consciousness: a practical scale. Lancet 1974 ;ii:81-3.

(Accepted 6 August 1987)

Regional Department of Child and Adolescent Neurology, Booth Hall Children's Hospital, Blackley, Manchester M9 2AA

C M BENJAMIN, MRCPI, registrar

R W NEWTON, MD, MRCP, consultant paediatric neurologist

M A CLARKE, MRCP, consultant paediatric neurologist

Correspondence to: Dr Newton.

.
, 